\title{
A CUSTOMER-CENTRIC APPROACH TOWARDS EVALUATING SINGLE- CHOICE INFORMATION TECHNOLOGY SERVICE PROVISION TO THE parastatal Sector of South Africa
}

\author{
MC Cant, JW Strydom, VM Moodley and DH Tustin
}

\begin{abstract}
The article presents a case study whereby the service performance of a single-choice information technology service provider in the parastatal industry of South Africa is measured against multichoice private service providers without any provisional agreements. The outcome of the case study reveals that single-choice service provision options with provisional agreements have a limited chance of success if they are not supported by strong service user inputs. In fact, provisional strategies that disallow sound competition among service providers are bound to impact negatively on user preferences as well as information technology skills development opportunities that are required to improve service provision generally, and long-term survival in particular.
\end{abstract}

JEL L33, 86

\section{1 \\ Introduction}

Since 2000, the information technology parastatal industry of South Africa has witnessed restructuring initiatives featuring the consolidation of information technology functions into a single-choice service provider format (Department of Public Enterprises, 2000). Alongside these developments, enabling agreements were fixed with various parastatals which restrict information technology demands to a single-choice service provider.

The Enabling Agreement (EA) in the parastatal industry of South Africa argues that the single-service information technology provider will have 'first right of refusal' over all information technology services required by its final customers. The implication of this agreement is that service users in the parastatal industry can only engage the services of other service providers if the newly established service provider is unable to provide the services required, or if it specifically refuses to perform work requested, or if agreements with other service providers existed prior to the formation of the newly formed service provider.
The enabling agreement has caused huge frustration and dissatisfaction among service users who now are limited to a single-information technology service supplier. Having been exposed to private service providers in the past and in some cases still dealing with them, they want choice of preference. This frustration/ dissatisfaction is further triggered by a sense among service users that their information technology needs are largely unmet in the parastatal industry, mainly due to a lack of understanding of their strategic needs. Poor service delivery and inadequate skills to effectively resolve service problems further place a threat on the ability of service users to meet their own organisationally imposed performance targets. Ultimately, the turmoil of activities in the information technology environment of the parastatal industry of South Africa has caused uncertainty and low confidence among service users.

\section{2}

Aims

Key to addressing these uncertainties and as an effort to contribute to potential solutions to 
change the negative perceptions and efficiency of the information technology parastatal industry, this article presents the views of parastatal organisations (service users) regarding key criteria for service delivery measurement. The customer analysis is presented in the form of a competitive model whereby information technology service delivery performance levels of a single parastatal service supplier are measured against private service suppliers. To meet this endeavor, the following null and alternative hypothesis was formulated:

$\begin{array}{ll}\mathrm{H}_{0}: & \mu_{1}=\mu_{2} \\ \mathrm{H}_{1}: & \mu_{1} \neq \mu_{2}\end{array}$

Here $\mu_{1}$ and $\mu_{2}$ represent the population average satisfaction levels with service performance for the single parastatal service provider and private service providers respectively.

The null hypothesis sets to test whether the average service performance levels of the single parastatal service and private service providers differ significantly. For those service performance measures that show statistically significant differences, the under- or overperformance levels of the single parastatal service provider could be identified with the aim of improving future customer relations, skills and service performance levels in the parastatal industry of South Africa. The outcome of the customer analysis presents a sound service delivery framework that the parastatal and broader information technology service industry can utilise to improve quality service delivery in general, and skills in particular.

\section{3}

\section{Research methodology}

A descriptive research model was designed in support of the customer analysis. As input to designing a research instrument to collect primary data among parastatals using information technology services, an adjusted version of Aaker's (1998) service delivery framework model was used. The model's framework was particularly suited to the customer-focused service delivery elements that were being evaluated for the purposes of this study. The service delivery framework model is discussed below.

A self-administrated survey approach was used to collect primary data among 90 key parastatal IT management staff (total population). For this purpose a research instrument (questionnaire) was designed. The questionnaire measured 25 service delivery criteria on a 10-point Likert scale. A full 83.3 per cent of the parastatal respondents self-completed and returned the questionnaire. Given the nature of the customers' business, representation from IT service providers constantly targets the organisation to sell products and services that are identical or very similar to those of the single-choice service provider. As a result, the organisation's respondents are appropriately qualified to compare and evaluate the relative quality of service offerings of the single-choice parastatal service provider against those of private service providers. All responses were edited, coded, captured and analysed to finally allow for some interpretations related to the study aims outlined above.

\section{4}

\section{Service delivery framework model}

Aaker's (1998: 45) service delivery framework focused on the following broad areas:

- Customer segmentation and fulfilling customer needs

- Customer motivations to purchase

- Unmet needs of customers and/or customer dissatisfaction

Based on the nature of the information technology service delivery environment in South Africa, the framework model outlined above was modified slightly by separating 'unmet needs of customers and/or customer dissatisfaction'. Furthermore, 'customer segmentation and fulfilling customer needs' was amended to 'customer segmentation and the ability to fulfill customer needs competently'. Finally, the four identifiable components of service delivery comprised different criteria specifically related to service delivery and the quality thereof. The 
four service delivery parameters as well as the criteria for service delivery at each level are illustrated in Table 1 below.

\section{Table 1}

Service delivery framework

\begin{tabular}{|c|c|}
\hline Service delivery parameter & Criteria for service delivery measurement \\
\hline $\begin{array}{l}\text { Customer segmentation and } \\
\text { the ability to fulfill customer } \\
\text { needs competently }\end{array}$ & $\begin{array}{l}\text { - } \text { Current offerings in line with unique needs of the business } \\
\text { - } \text { - Delivers vervice to meet changing needs } \\
\text { - IT services properly defined in Service Level Agreement (SLA) } \\
\text { - SLA effectively controls quality of service } \\
\text { - Service quality meets industry standards } \\
\text { - }\end{array}$ \\
\hline $\begin{array}{l}\text { Ability to understand customer } \\
\text { motivations to purchase } \\
\text { services effectively }\end{array}$ & $\begin{array}{l}\text { - Knowledge of business model } \\
\text { - } \text { - Strategic understanding of challenges facing the industry } \\
\text { - Understands how industry challenges will affect the business } \\
\text { - SP possesses expertise required } \\
\text { - SP possesses transformational skills to help the business } \\
\text { - Willingness to purchase regularly from SP } \\
\text { - SP preferred as supplier of choice in future }\end{array}$ \\
\hline $\begin{array}{l}\text { Establishing unmet customer } \\
\text { needs }\end{array}$ & $\begin{array}{l}\text { - Regularly provides creative solutions not yet considered } \\
\text { - Proactive provision of R\&D information for the business } \\
\text { - Demonstration of thought leadership in the IT field } \\
\text { - Thought leadership advisor of choice for the business }\end{array}$ \\
\hline $\begin{array}{l}\text { Overall customer satisfaction } \\
\text { with service delivered }\end{array}$ & $\begin{array}{l}\text { - IT service problems resolved within agreed times (as specified in service } \\
\text { level agreements - SLAs) } \\
\text { - } \text { All complaints followed up efficiently } \\
\text { - } \text { Regular feedback provided on the status of serious problems being } \\
\text { - Service staff perceived as reliable and well-skilled in providing the } \\
\text { required service } \\
\text { - The service provider regularly delivers high quality proposals for new } \\
\text { work (ie error free and timely delivery) } \\
\text { Satisfaction with the overall level of service provided by the service } \\
\text { provider }\end{array}$ \\
\hline
\end{tabular}

The four components of service delivery that comprise the customer analysis are discussed below to provide further insight into the parameters of the study. The specific need for information on each level is also highlighted in the discussion below.

\subsection{Customer segmentation and fulfilling customer needs competently}

In pursuing effective customer segmentation, it was found that meaningful improvements in sales arose from segmenting customers 
more thoughtfully, serving those segments more efficiently and staffing the organisation at the right level to attend to those segments appropriately (Waaser, Dahneke, Pekkarinen \& Weissel, 2004: 105-111). For the case study it was initially unclear whether careful segmentation was done with the aim of becoming better acquainted with customer needs and requirements, hence the need for the study to be conducted. Grönroos (2001: 63) identified a tendency, especially among technology- oriented firms, to focus on the technical specification of a service rather than the customer concept of quality. The author also found that customers often perceive their experience of quality to be a much broader concept than merely the technical aspects of a firm's service or product offering. Grönroos further advises that the organisation should define and view quality from the customer's perspective rather than its own in order to avoid expending time money and effort on misguided efforts arising out of a narrow and internal focus. Seybold (2001: 81) concurs with this view, and further identifies the tendency among organisations to focus excessively on fine-tuning their own services and products to the extent that they neglect understanding the impact of those offerings on their customers and the environment in which they operate. The possibility existed that this could also be the case with a single parastatal service supplier's approach to conducting business with its customers, hence the need for this study.

The importance and relevance of customer segmentation is highlighted in a study conducted among various industries in South Africa, namely information technology, industrial gases, car rental, engineering and packaging (Gilbert: 2002a). Two main issues raised by this study was firstly that a distinct lack of market segmentation was practised by the majority of organisations, and secondly that there was a tendency towards a 'one-size-fits-all' approach. The overall conclusion of the study was that it is important to segment markets in order to target attractive customers, while delivering clear marketing messages tailored to each identifiable segment.

Effective segmentation and viewing problems from the perspective of the customer alone are insufficient in addressing customer needs competently. Over the lifetime of an organisation, conflicts with customers due to service failure are inevitable. However, the effort and time taken to rectify such problems and to recover from service failures will help the organisation to achieve and solidify customer satisfaction (Tax \& Brown, 1998: 87). The authors argue that organisations should focus their attention increasingly on strategies aimed at satisfying and keeping current customers, as opposed to exclusively seeking out new customers. For the case study, the Enabling Agreement (EA) guarantees the organisation of revenue and contracts from parastatal customers, while it is also allowed to seek out new customers from the public and private sectors. It is not inconceivable that the existence of the EA, guaranteeing captive customers, may be a source of frustration arising from the parastatal customers feeling neglected by the single parastatal service provider as it pursues its other objectives of acquiring new customers at the expense of service to existing customers effectively.

\subsection{Ability to understand customer motivations to purchase effectively}

Understanding customers' motivations to purchase are important in guiding the organisation towards a service delivery model that will enable appropriate interaction for effective and efficient service delivery. Hutt and Speh (2004: 59) consider this understanding to be crucial for identifying profitable segments of the organisational market, for locating buying influences within these segments and for reaching the organisational buyers within these segments efficiently and effectively with offerings that respond to their needs. In organisations that have many buying centres, it is imperative that the service provider focuses its attention on the members of buying centres, as each has a unique personal and organisation frame of reference that has a direct bearing on the buying decision (Hutt \& Speh, 2004: 84). The single parastatal service provider's customers are sufficiently large organisations with multiple business units that conduct the purchasing of products and services independently of each other. These 
parastatals are all undergoing transformation in order to meet the governmental agendas and social challenges that now face the country. As a result, increasing competitive pressures facing these organisations and the industries within which they operate are inevitable. Few organisations can avoid getting to know as much as possible about the people and/or the organisations that comprise the potential targets in a market (Watters, 1995: 65). Understanding its customers' motivations to purchase is therefore an important task for a single parastatal service provider that goes beyond superficial and rudimentary analyses of its customers, towards an in-depth knowledge of the organisations it services and the environmental forces shaping them.

Customer motivations may also have implications for a single parastatal service provider. Gilbert's (2002b: 8-9) discussion of the study conducted by an Ohio-based consulting organisation on the critical sales practices of exceptional sales forces, deals with certain issues that have implications for customer motivation in their business decision making. The study concluded that there is a growing need among customers to have supplier organisations move closer to them and to have employees from supplier organisations empowered with decision-making authority to promote flexibility and speed-up service delivery. The intention of this section was to establish whether the single parastatal service provider possesses adequate understanding of the environment in which it operates. This section also investigated whether the single parastatal service provider is perceived as being appropriately skilled. The final two questions in the section relate to whether service users would prefer to make regular purchases from the single parastatal service provider, and whether it is considered a supplier of choice for the future.

\subsection{Establishing unmet customer needs}

Aaker (1998: 53) considers customers' unmet needs to be those needs that are not being met by existing product offerings. Rather than merely asking customers for their requirements, some organisations succeed by innovatively leading customers proactively towards where they are heading before they realise that it is necessary (Hutt \& Speh, 2004: 315-316). In order to do this, deep insights are required into the needs of current and future customers to enable the organisation to plan and execute such initiatives. "Today customers want commitment from those who serve them. In our diverse and turbulent markets, some customers want respect as individuals; others seek consistency; more customers expect suppliers to learn to keep track of their changing lifestyles; in addition they require value for money in terms of their available incomes" (Shaw, 1996: 71). Shaw's observation applies equally to the single parastatal service provider and the expectations that its parastatal customers have of it.

Successful identification of unmet customer needs may have significant implications for the organisations that initially discover them, because they could result in a competitive advantage for the organisation, especially in highly competitive industries (Urban \& Hauser, 2002: 22). Unmet needs afford an organisation opportunities to increase market share or access other markets that would ordinarily be difficult to penetrate using conventional techniques. Regular discovery of these needs may be more important in certain industries than in others. In high-tech industries such as the one in which the single parastatal service provider operates, changes are rapid and product obsolescence cycles short. Hence current market research analyses may not be as reliable for the purposes of discovering and satisfying customer needs in businesses dealing with high-tech products (Von Hippel, 1986: 791). The study conducted with service users involved an understanding of whether the single parastatal service provider possessed adequate knowledge and capacity to understand the customer's energy business environment in particular and the energy industry in general. Moreover, the study sought to uncover whether the single parastatal service provider was appropriately equipped to help service users through crucial transformation that it is currently undergoing in the information technology and information management processes in its business environment. 


\subsection{Overall customer satisfaction with service delivered}

Customer dissatisfaction (or satisfaction) relates to a comparison of customer expectations about a particular product and supporting service against the actual performance of the product and supporting services (Cravens, 1997: 143). However, prior experience may also provide a basis of comparison of such expectations. Experiences with poor-quality products or services often generate customer dissatisfaction. Hence a dissatisfied customer could conceivably tell up to eleven other people of his or her dissatisfaction with an organisation's service and/or products, which is two to three times more people than a satisfied customer is likely to speak to if he or she experiences good service (Brassington \& Pettitt, 1997: 95).

The study conducted among service users also reviewed its overall satisfaction with the quality of the single parastatal service provider's service delivery. Service quality is best conceptualised as an attitude based on the customer's "perceptions" of performance (Nowak \& Wasburn, 1998: 442). Barnes (2001: 33) reflected on the correlation of customer satisfaction to the value derived from their interactions with the organisation selling the relevant product or service. He concluded that organisations need to go beyond viewing customers as targets to whom organisations merely sell products and services, and that they need to define value more broadly than product and price alone. By implication the authors advocate that organisations move beyond viewing the customer as a commodity towards valuing the customer in a manner that is reflected in the attitude adopted towards the quality of service delivery and resultant customer satisfaction.

\section{Analysis of research results}

Given that the research problems/aims are based on the outcome of the stated hypothesis, the analysis below features the results of the paired sample t-test. This test was applied to determine statistically significant differences in the average performance levels of the singlechoice parastatal service provider and private service providers. As a result, this test enables us to evaluate whether there is a need for customer analysis by single-choice parastatal service providers, who compete against private service providers who actively attach importance to such a practice. The paired sample t-test analysis is presented in Table 2. 


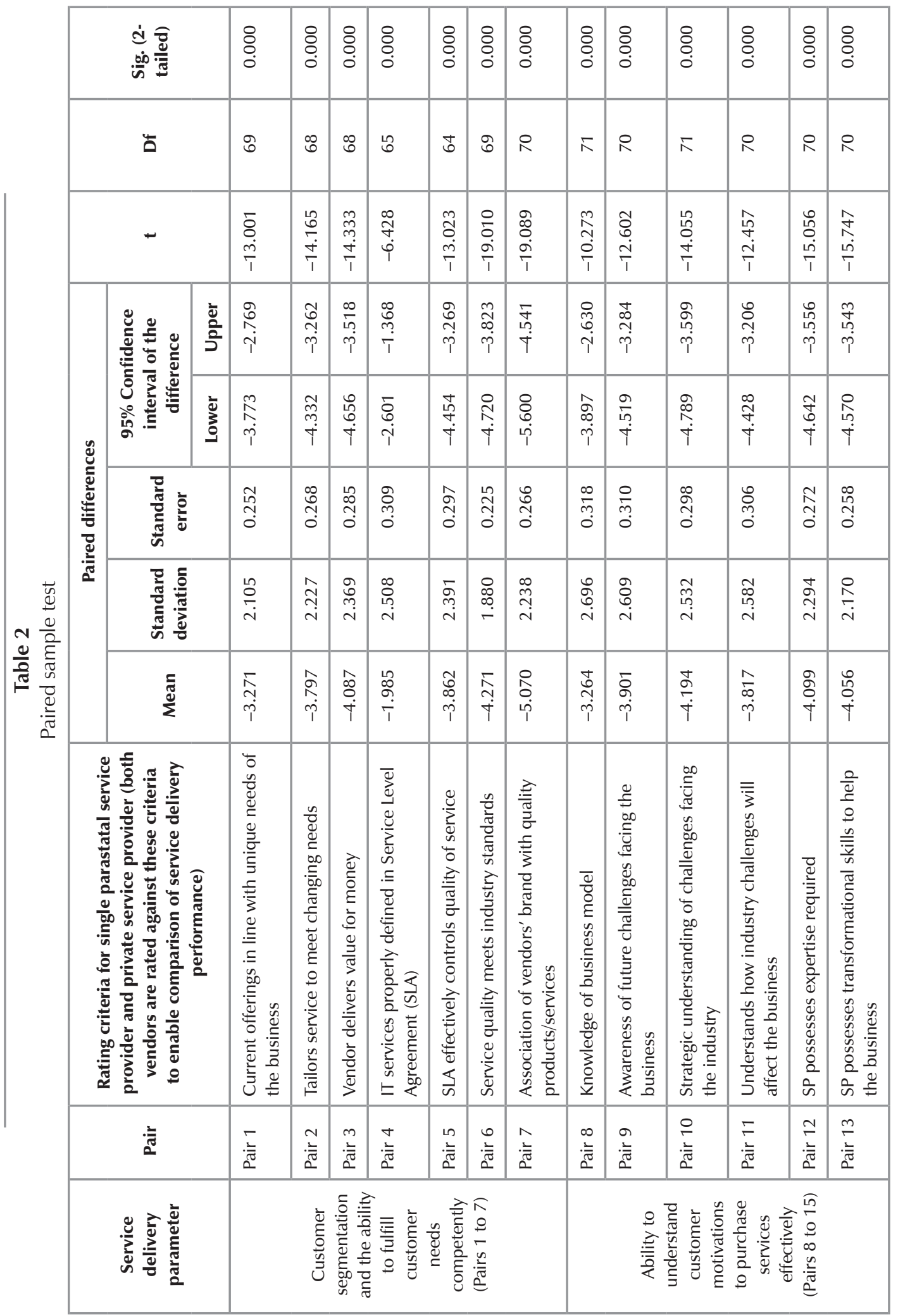




\begin{tabular}{|c|c|c|c|c|c|c|c|c|c|c|c|c|c|c|}
\hline & 宊 & & $\begin{array}{l}8 \\
\& \\
0\end{array}$ & $\begin{array}{l}8 \\
\stackrel{0}{0} \\
\dot{0}\end{array}$ & $\begin{array}{l}8 \\
\& \\
0\end{array}$ & $\begin{array}{l}8 \\
\stackrel{0}{0} \\
0\end{array}$ & $\begin{array}{l}8 \\
\stackrel{0}{0} \\
0\end{array}$ & $\begin{array}{l}8 \\
\& \\
0\end{array}$ & $\begin{array}{l}8 \\
\stackrel{0}{0} \\
0\end{array}$ & $\begin{array}{l}8 \\
\& \\
0\end{array}$ & $\begin{array}{l}8 \\
\vdots \\
0\end{array}$ & $\begin{array}{l}8 \\
\& \\
0\end{array}$ & $\begin{array}{l}8 \\
\vdots \\
0\end{array}$ & $\begin{array}{l}8 \\
\& \\
0\end{array}$ \\
\hline & 吉 & & $R$ & 이 & 이 & రి & $\stackrel{R}{R}$ & $\ddot{\sigma}$ & ? & $\stackrel{0}{0}$ & ๑ొ & $\stackrel{R}{R}$ & oి & gి \\
\hline & - & & 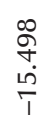 & 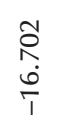 & $\begin{array}{l}\infty \\
0 \\
\stackrel{0}{1} \\
\text { Tे }\end{array}$ & $\begin{array}{l}N \\
\infty \\
\infty \\
\infty \\
1\end{array}$ & $\begin{array}{l}\text { के } \\
\stackrel{0}{0} \\
\text { Tे }\end{array}$ & 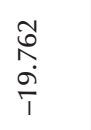 & $\begin{array}{l}\infty \\
\stackrel{\infty}{\circ} \\
\stackrel{+}{+} \\
\end{array}$ & 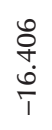 & $\begin{array}{l}\bar{\delta} \\
\text { m. } \\
\stackrel{1}{1} \\
1\end{array}$ & $\begin{array}{l}1 \\
\infty \\
N \\
\infty \\
T\end{array}$ & $\begin{array}{l}\infty \\
\stackrel{2}{1} \\
\frac{0}{1}\end{array}$ & $\begin{array}{l}\infty \\
\infty \\
0 \\
\infty \\
1\end{array}$ \\
\hline & 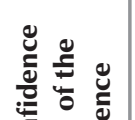 & $\frac{\grave{2}}{\frac{2}{2}}$ & 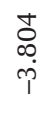 & $\begin{array}{l}\infty \\
\substack{\infty \\
m \\
+} \\
+1\end{array}$ & $\begin{array}{l}\stackrel{0}{0} \\
\stackrel{0}{+}\end{array}$ & $\begin{array}{l}\stackrel{2}{N} \\
\stackrel{+}{T}\end{array}$ & $\stackrel{\frac{10}{m}}{\stackrel{T}{T}}$ & $\begin{array}{l}\stackrel{+}{O} \\
+ \\
+ \\
+\end{array}$ & $\begin{array}{l}m \\
\infty \\
\infty \\
i\end{array}$ & 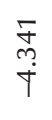 & $\begin{array}{l}\stackrel{0}{\text { hn }} \\
\stackrel{+}{\dagger}\end{array}$ & $\begin{array}{l}\text { m } \\
\ddot{O} \\
\dot{+}\end{array}$ & $\stackrel{n}{\tilde{\sigma}}$ & $\begin{array}{l}\stackrel{p}{N} \\
\stackrel{p}{\dagger}\end{array}$ \\
\hline & 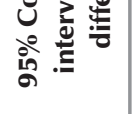 & 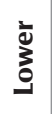 & $\begin{array}{l}\text { o } \\
\text { ơ } \\
\text { † }\end{array}$ & 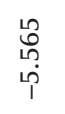 & 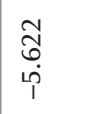 & $\begin{array}{l}0 \\
\stackrel{0}{\infty} \\
\infty \\
\text { ip }\end{array}$ & $\begin{array}{l}\bar{N} \\
\stackrel{i}{p}\end{array}$ & $\begin{array}{l}\bigcap_{m} \\
\text { p. } \\
\text { p. }\end{array}$ & 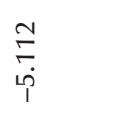 & $\begin{array}{l}\frac{m}{L} \\
\text { Ln } \\
\text { in }\end{array}$ & $\begin{array}{l}\infty \\
\infty \\
m \\
i p \\
i p\end{array}$ & $\begin{array}{l}\text { Lo } \\
\text { Lे } \\
\text { Lे }\end{array}$ & $\begin{array}{l}\stackrel{+}{h} \\
\stackrel{1}{1} \\
\stackrel{1}{1}\end{array}$ & 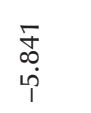 \\
\hline 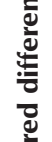 & 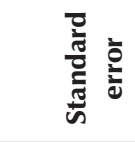 & & $\begin{array}{l}\text { ô } \\
\text { đֶ } \\
0\end{array}$ & $\begin{array}{l}\text { ڤั } \\
\text { ֶె }\end{array}$ & 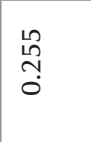 & $\begin{array}{l}\bar{\infty} \\
\stackrel{y}{0} \\
0\end{array}$ & $\begin{array}{l}\stackrel{L}{+} \\
\text { J }\end{array}$ & 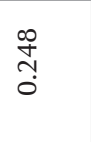 & $\stackrel{\infty}{\tilde{m}}$ & $\begin{array}{l}\bar{\sigma} \\
\text { ֶ. } \\
0\end{array}$ & 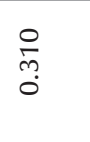 & $\begin{array}{l}\stackrel{\text { Tे }}{\mathrm{O}} \\
\text { }\end{array}$ & $\begin{array}{l}10 \\
\text { o } \\
\text { y } \\
0\end{array}$ & 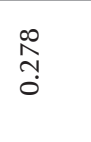 \\
\hline $\bar{a}$ & 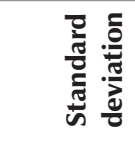 & & $\begin{array}{l}\stackrel{+}{N} \\
\stackrel{N}{N}\end{array}$ & $\begin{array}{l}\stackrel{\&}{+} \\
\text { i }\end{array}$ & 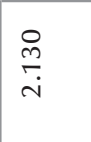 & $\underset{m}{m}$ & $\begin{array}{l}\bar{\delta} \\
\text { ì }\end{array}$ & $\begin{array}{l}\text { ஜ̂ } \\
\text { ì }\end{array}$ & $\begin{array}{l}\text { ô } \\
\text { ì } \\
\end{array}$ & 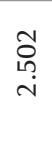 & 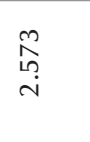 & $\begin{array}{l}\text { o̊ } \\
\text { ì }\end{array}$ & 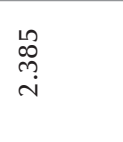 & $\begin{array}{l}\text { ते } \\
\text { } \\
\text { in }\end{array}$ \\
\hline & $\sum^{\Sigma}$ & & $\begin{array}{l}\stackrel{0}{0} \\
\stackrel{m}{+} \\
+\end{array}$ & $\begin{array}{l}\nwarrow \\
\text { o } \\
\stackrel{+}{1}\end{array}$ & 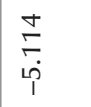 & $\begin{array}{l}8 \\
\text { ì } \\
\text { ị }\end{array}$ & $\begin{array}{l}m \\
0 \\
\infty \\
+\end{array}$ & $\begin{array}{l}\text { के } \\
\infty \\
+\end{array}$ & 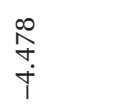 & $\stackrel{\text { Ỹ }}{\stackrel{+}{+}}$ & $\begin{array}{l}\stackrel{\infty}{\circ} \\
\stackrel{+}{+} \\
+\end{array}$ & 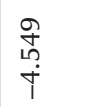 & $\frac{\infty}{\stackrel{\infty}{\dot{\varphi}}}$ & $\begin{array}{l}0 \\
\stackrel{0}{0} \\
\stackrel{1}{1} \\
i \\
1\end{array}$ \\
\hline & 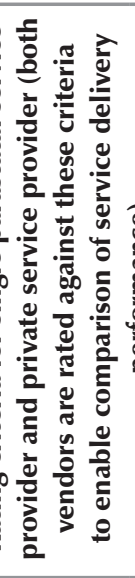 & & 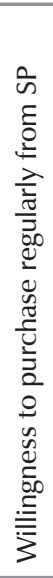 & 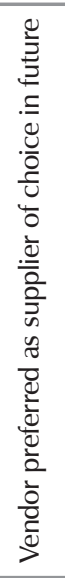 & 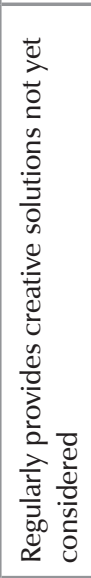 & 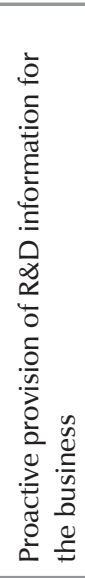 & 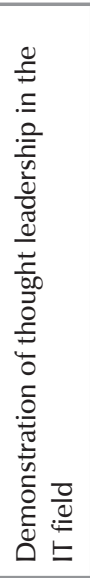 & 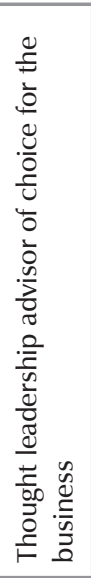 & 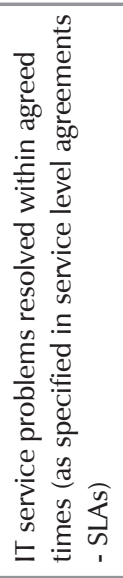 & 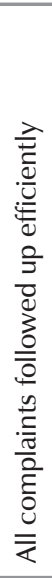 & 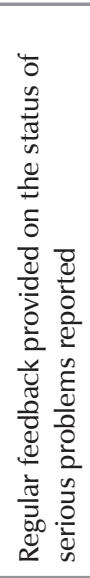 & 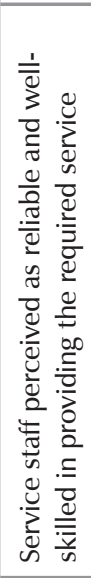 & 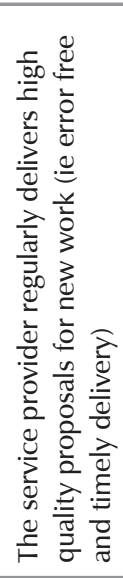 & 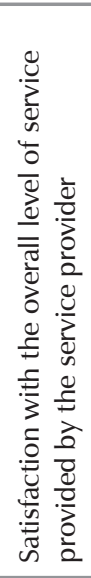 \\
\hline & 訔 & & $\frac{\pi}{\stackrel{\pi}{\pi}}$ & 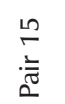 & $\begin{array}{l}0 \\
\stackrel{\bar{\pi}}{\pi} \\
2\end{array}$ & $\frac{1}{\stackrel{5}{\circ}}$ & $\stackrel{\infty}{\frac{\infty}{\pi}}$ & $\frac{\sigma}{-\pi}$ & 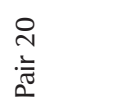 & $\begin{array}{l}\bar{N} \\
. \bar{\pi} \\
\overline{2}\end{array}$ & 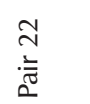 & 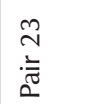 & 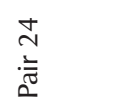 & $\stackrel{\stackrel{L}{N}}{\stackrel{ \pm}{\pi}}$ \\
\hline & 总 & & & $\underset{\stackrel{8}{0}}{\stackrel{8}{0}}$ & & 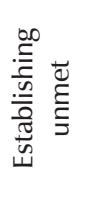 & 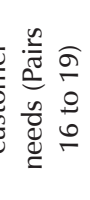 & & & & 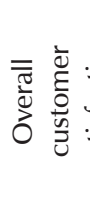 & 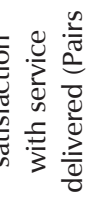 & & \\
\hline
\end{tabular}


The output of the paired sample t-test reflects the means and standard deviations of the two variables, and their standard error, confidence intervals and the differences between the means and their standard error. The $t$-value and associated two-tailed probability are also shown. The $t$-value is calculated using the following formula:

$$
t=\frac{x_{1}-x_{2}}{\sqrt{\frac{s^{2}}{n}}}
$$

Table 2 shows the mean scores that reflect the difference between the average service performance ratings provided to the different service performances of the single parastatal service provider and private service providers. The significant test statistics (Sig. 2-tailed) for all service criteria indicates that all 25 service criteria evaluations for the single parastatal service provider and other service providers are not the same $(\mathrm{p}<0.05)$. The null hypothesis $\left(H_{0}: \mu_{1}=\mu_{2}\right)$ that the mean difference between the average ratings for the single parastatal service provider and other service providers are the same (zero), is therefore rejected for all service delivery and provision criteria in favour of the alternate hypothesis $\left(H_{i}: \mu_{1} \neq \mu_{2}\right)$. The hypothesis that the mean difference between the average ratings for the single parastatal service provider and other service providers are the same (zero) is therefore rejected for all service delivery and provision criteria. The difference observed between the service performance of the single parastatal service provider and private service providers was due to a chance less than 5 out of 100 times. Indeed, judging from the average mean values of the sample statistics, the average service performance ratings are lower for the single parastatal service provider on all 25 service delivery criteria.

Based on the analysis presented above, as well as the broad objectives, each service delivery parameter merits some final comments.

\subsection{Customer segmentation} (Table 2, Pairs 1 to 7)

The poor customer perception ratings for the single parastatal service provider indicate problems and areas of concern with regard to the following:

- Managing the perception of value delivered to service users (in essence delivering value for money).

- Information Technology services being better defined in the service level agreement (SLA) and effective quality control using the SLA as well as other tools.

- Managing customer perception of whether quality standards currently set by single parastatal service provider meet industry standards.

- Management of the quality of services and products rendered such that the perception of the quality brand is perceived in a more positive light.

From the above analysis it is therefore clear that the single-choice service provider's management of customer perceptions with regard to the delivery of value for money is quality of its service and the effective management of SLAs. In essence, the single-choice service provider has not created a brand that is held in as high regard as that of the private service providers.

These indicators may in themselves not be key factors in influencing the decisions of customers to switch from one service provider to another. However, they could lay the foundation for a broader perceptual framework that governs how the organisation is regarded over time, and will affect its standing with customers when decisions need to be made with regard to periods beyond those timeframes governed by the initial enabling agreement. Indeed, the South African parastatal Transnet has already decided to "source its IT expertise and resources from the most cost-efficient source - be that internal or external" (Vegter, 2005: 32). Vegter further quotes the Chief Information Officer of Transnet as saying that "It would be irresponsible to use internal monopolies when we could go to the market for a more cost-effective solution." As a result, it is clearly in the interests of long-term survival for the single-choice service provider to adopt a more customer-centric approach. 


\subsection{Customer motivations (Table 2, Pairs 8 to 15)}

The implications of the low ratings for the single-choice service parastatal provider are the following:

- It is perceived as not being sufficiently knowledgeable and proficient in order to assist service users with effective organisational transformation to meet future challenges that are likely to affect it.

- The ratings depict the single-choice service provider as an organisation from which service users are unwilling to make regular voluntary purchases.

While it is understandable that the single-choice service provider is a relatively new organisation as a combined business entity, it nevertheless arose from the parastatal environment that it is supposed to understand intimately with regard to the manner of operation and its strategic planning for the future. As a result, it should use this knowledge as a source of advantage. However, given the subsequent allocation of roles to different managers, resulting in certain managers being taken away from customer portfolios that they had intimate knowledge of, such advantage was eroded over time. As a result, valuable customer-specific knowledge had to be re-acquired while private service providers were able to acquire new and more intimate knowledge for strategic planning that the customer considered to be of greater use.

\subsection{Unmet customer needs (Table 2, Pairs 16 to 19)}

The private service provider scored highest for proficiency of thought leadership and for the provision of creative solutions that were not yet considered. The equal mean ratings were also favourable for the private service provider when it came to proactive provision of research and development and also for being the thought leadership provider of choice. Overall, the single-choice parastatal service provider was rated below the private service providers. From the analysis of the results in this section it is clear that the single-choice service provider has not considered the need to be proactive and to demonstrate thought leadership for the sake of future-oriented solution crafting to be an imperative. This tendency is understandable given its previous manner of operation as a collection of IT departments within the parastatal environment prior to consolidation as a singlechoice service provider. The transition from an internal department to an external business entity as a single-choice service provider did not encompass the change from a reactive business outlook to one of proactive service management and solution delivery as in the case of private service providers, nor was it apparent during the transition phase that such preparations would be vital in assisting the entity to adapt to its new role in a challenging and diverse environment. Such preparatory steps, as are discussed in the concluding section of this article, will need to managed as a matter of priority if the state and the various parastatals intend continuing with such programmes in efforts to seek greater efficiencies from their assets.

\subsection{Customer dissatisfaction} (Table 2, Pairs 20 to 25)

Overall, the single-choice service provider performed worse than the private service providers across all criteria. This indicates a general level of customer dissatisfaction by service users with the single parastatal service provider, while the corresponding overall rating for the private service providers indicates a great degree of satisfaction with the quality of services received. While these results may seem obvious, the underlying message from the study has implications for the manner in which organisations undergoing such transitions address customer dissatisfaction in future. While the single-choice service provider may be providing the same function as the private service providers, the time taken to resolve complaints, the quality of documentation produced and the perception of the skills and abilities of service staff are of great concern to customers. Merely having the functions in place does not suffice, given that a higher quality of service is required in all areas in order to address 
customer satisfaction comprehensively. The study results would seem to indicate that a "good enough" approach was striven for by the singlechoice service provider, while private service providers focused on understanding customer expectations and meeting or exceeding these as a matter of priority.

\section{6}

\section{Conclusions drawn from the study}

The broad conclusion drawn from this study is that the single-choice service provider does not attach sufficient importance to the need for customer analysis or service delivery, and this is substantiated by the results achieved in each component of the study. The presence of other competitors and the consistency with which the single-choice service provider has been outperformed by those organisations on the various criteria seem to indicate that service users are seeking alternatives where possible in order to prevent needless exposure to perceived poor performance from the single-choice service provider.

The research study has clear implications for the state's future planning and policy with regard to privatisation, as well as for large private organisations considering the unbundling of specific functions or entities (such as information technology departments or internal consulting departments) that exist within them. Large organisations and public utilities often develop cultures that emphasise entitlement and complacency, while lacking sufficient focus on entrepreneurial capability and customer centricity. It would seem that such has been the case with the single-choice service provider who was accustomed to a parastatal environment, and was evidently lacking in customer analysis capability, resulting in the performance discussed above. In reviewing the issue of culture in this context, the matter of recruiting the appropriate calibre of leadership can hardly be emphasised more, as this is the foundation upon which a successful transformation rests. This study has thus demonstrated the importance of leadership action focused on creating a customer-centric and service-oriented paradigm that actively supercedes the original parastatal mindset and foundation. Invariably, the importance of appointing suitable leaders who possess appropriate levels of emotional intelligence and technical proficiency should therefore not go unnoticed, as a rule rather than the exception.

The research shows clearly that the single-choice service provider, who/that was accustomed to a parastatal environment where entrepreneurial activity and competitor intelligence gathering were never operational requirements, was not adequately prepared for the transition to a commercial entity. While the EA is able to provide the organisation with a finite source of protection from competition in the open market, the single-choice service provider may not be doing enough to build sufficient goodwill and a reputation within the existing customer base, primarily because it was never considered to be a priority during the strategic planning and organisational design process.

In many industries, such as the information technology industry, change is rapid and technology obsolescence is the rule rather than the exception. Organisations therefore do not have the luxury of many years within which to evolve a successful business model fashioned from errors made during the formative years of operation. Customer analysis is therefore an important tool that can be used to help organisations to focus on imperatives that are universally applicable and attributable to most, if not all, businesses.

The paired sample model can further be used to prioritise strategies to improve service delivery and provision. The observed values obtained from the research conducted herein should serve as a guide to all organisations in South Africa undergoing similar transformation, in addressing areas of management that are likely to affect these organisations and their present and prospective customers. Four key areas, namely customer segmentation, customer motivations to purchase, unmet customer needs and customer dissatisfaction, can now serve as a guide for initiatives to bring about organisational improvement.

The research described herein demonstrates the value of customer analysis for organisations 
undergoing transformation to operate in new industries or environments. In South Africa, and indeed worldwide, state-owned organisations are increasingly required to either privatise or corporatise in order to operate in ways that mirror the performance of successful organisations in the private sector. Many such organisations would typically arise from resource-abundant, protected environments that do little to prepare them for operations in fast-paced, results-oriented environments. Prior leadership and organisational management practices and experiences and institutional cultures may therefore serve as inappropriate preparation for the management of the new organisations that result from privatisation or unbundling initiatives. Customer analysis and customer centricity are key imperatives that most private-sector-oriented organisations naturally incorporate into their business cultures, but which organisations in protected environments are less likely to be aware of at their time of transition. As a result, customer analysis can be a useful tool to help organisations to focus increasingly scarce resources on areas of operation that are likely to produce the best results, while protecting its most important asset, namely its customers.

\section{References}

1 AAKER, D.A. (1998) Strategic Market Management, (5th ed.) John Wiley: New York.

2 BARNES, J.G. (2001) Secrets of Customer Relationship Management: It's all about how You Make Them Feel, McGraw-Hill: New York.

3 GILBERT, P. (2002a) "Benchmarking sales", IMM Journal of Marketing, 8(1): 8-9.

4 GILBERT, P. (2002b) "Outdated sales approaches erode corporate profits”, IMM Journal of Marketing, 8(2): 8-9.

5 GRÖNROOS, C. (2001) Service Management and Marketing: A Customer Relationship Management and Approach, (2nd ed.) John Wiley \& Sons: New York.

6 HUTT, M.D. \& SPEH, T.W. (2004) Business Marketing Management: A Strategic View of Industrial Markets, (8th ed.) Thomson SouthWestern: Ohio.

7 NOWAK, L.I. \& WASBURN, H.J. (1998)

"Antecedents to client satisfaction in business services”, The Journal of Services Marketing, 12(6): 441-452.

8 SEYBOLD, P.B. (2001) "Get inside the lives of your customers", Havard Business Review, 79(5): 81-89.

9 SHAW, R. (1996) "Creating a ring of commitment to customers", Journal of Marketing Practise: Applied Marketing Science, 2(3): 71-92.

10 TAX, S.S. \& BROWN, S.W. (1998) "Recovering and learning from service failure", Sloan Management Review, 40(1): 75-88.

11 URBAN, G.L. \& HAUSER, J.R. (2002) "Listening in to find unmet customer needs and solutions", http://www.mitsloan.mit.edu/vc.

12 VEGTER, I. (2005) "Transnet: Open purse no more", CIO Africa, Quarter 1: 30-32.

13 VON HIPPEL, E. (1986) "Lead users: A source of novel product concepts", Management Science, 32(7): 791-805.

14 WAASER, E.; DAHNEKE, W.; PEKKARINEN, M. \& WEISSEL, M. (2004) "How you slice it: Smarter segmentation for your sales force", Harvard Business Review, 82(3): 105-111.

15 WATTERS, R.G. (1995) "International business development - What are the considerations?", Journal of Business and Industrial Marketing, 10(3): 61-73. 